\title{
IMPLEMENTASI STRATEGI KAYANG TERHADAP KEBERHASILAN PAUD INKLUSI KASYA DAY CARE CENTER AND SCHOOL \\ BANDA ACEH
}

\author{
Yenni Muflihan \\ Sekolah Tinggi Ilmu Manajemen Indonesia- Meulaboh \\ yennimuflihan@gmail.com
}

\begin{abstract}
Abstrak
Pada dasarnya semua anak memiliki hak yang sama dalam mendapatkan pendidikan, tak terkecuali bagi Anak Berkebutuhan Khusus. Guru harus dapat mengerti dan memikirkan strategi pembelajaran apa yang sesuai bagi Anak Berkebutuhan Khusus, karena Anak Berkebutuhan Khusus memerlukan perlakuan yang istimewa dalam mendidik atau mengajarkan mereka. PAUD Inklusi merupakan lembaga pendidikan yang diperuntukkan bagi Anak Berkebutuhan Khusus, selain anak Berkebutuhan Khusus, banyak juga siswa yang mendaftar di PAUD Inklusi Kasya tersebut. Penelitian ini bertujuan untuk menganalisis penerapan strategi pembelajaran pada PAUD Inklusi Kasya Day Care Center and School Banda Aceh yaitu strategi "kayang", melalui metode library research. Dari hasil penelitian ini dapat disimpulkan bahwa strategi "kayang" memberikan dampak yang sangat besar terhadap kemajuan dan keberhasilan PAUD Inklusi Kasya Day Care Center and School Banda Aceh.
\end{abstract}

Kata kunci: Strategi Kayang, PAUD, Inklusi

\section{Abstract}

Basically, all children have the same rights to get education, including children with special needs. Teachers must be able to understand and think about what learning strategies are suitable for children with special needs, because children with special needs require special treatment in educating or teaching them. Inclusive PAUD is an educational institution intended for children with special needs, in addition to children with special needs, many students have also registered in Kasya Inclusion PAUD. This study aims to analyze the implementation of learning strategies in the Kasya Day Care Center and School Banda Aceh Inclusion PAUD, namely the "kayang" strategy, through the library research method. From the results of this study, it can be concluded that the "kayang" strategy has had a huge impact on the progress and success of the Kasya Day Care Center and School Banda Aceh Inclusion PAUD.

Key words: Kayang Strategy, PAUD, Inclusion

\section{PENDAHULUAN}

Pendidikan merupakan salah satu cara mencerdaskan generasi bangsa. Jadi semua orang berhak mendapatkan pendidikan, tidak terkecuali anak-anak yang berkebutuhan khusus.
Mereka mempunyai hak yang sama dengan anak normal lainnya. Lembaga pendidikan pada masa dahulu memisahkan anak yang normal dengan anak yang berkebutuhan khusus, akan tetapi pada masa sekarang sebagian lembaga 
pendidikan membuka pendaftaran untuk anak normal dan anak yang berkebutuhan khusus atau dikenal dengan sebutan pendidikan inklusi.

Menurut Hildegun Olsen dalam Tarmansyah (2007), pendidikan inklusi adalah sekolah harus mengakomodasi semua anak tanpa memandang kondisi fisik, intelektual, sosial emosional, linguistik atau kondisi lainnya. Ini harus mencakup anak-anak penyandang cacat, berbakat. Anak-anak jalanan dan pekerja anak berasal dari populasi terpencil atau berpindahpindah. Anak yang berasal dari populasi etnis minoritas, linguistik, atau budaya dan anakanak dari area atau kelompok yang kurang beruntung atau termarjinalisasi. ${ }^{1}$

Menurut Staub dan Peck dalam Tarmansyah (2007), pendidikan inklusi adalah penempatan anak berkelainan ringan, sedang dan berat secara penuh di kelas. Hal ini menunjukkan kelas regular merupakan tempat belajar yang relevan bagi anak-anak berkelainan, apapun jenis kelaminnya. ${ }^{2}$

Awal pendidikan formal yaitu PAUD (Pendidikan Anak Usia Dini). PAUD inklusi ini sangat penting khususnya bagi anak-anak berkebutuhan khusus. Dengan mengenal segala sesuatu yang ada di lingkungan sekitar dan bagaimana cara berinteraksi dengan orang lain serta penanaman nilai-nilai moral dan agama kepada anak-anak tersebut. fokus penelitian saya adalah pada PAUD Kasya Day Care Center and School. PAUD inklusi ini pada awalnya terkendala dengan susahnya mencari guru. Guru yang mendaftar di PAUD tersebut hanya bertahan selama beberapa waktu saja, kebanyakan berhenti kerja dikarenakan tidak

1 Tarmansyah. Inklusi Pendidikan untuk Semua. Jakarta: Depdiknas. 2007. Hlm. 82

2 Ibid., hlm.83 sanggup menghadapi tingkah laku anakanak tersebut, khususnya Anak Berkebutuhan Khusus (ABK). Permasalahan berikutnya adalah orang tua dari anak normal (Non ABK) yang pada awalnya ingin mendaftar di PAUD Kasya tersebut. Kebanyakan tidak jadi mendaftar karena orang tua tersebut takut anakanak mereka mengikuti tingkah laku ABK tersebut. Selain itu, ABK bertingkah laku tidak selazimnya seperti mengamuk-ngamuk tanpa sebab dan mengganggu teman-teman yang lain. Hal ini yang mendorong pengurus PAUD kasya tersebut memikirkan solusi apa yang dapat dilakukan untuk mengatasi masalah-masalah tersebut.

Sebelum jadi pengurus, pada tahun 2009 Ibu Saprina Siregar merupakan guru di PAUD Kasya tersebut. Akan tetapi pada tahun 2011, beliau menjabat sebagai pengelola PAUD Kasya dan dibawah kepemimpinan beliaulah PAUD Kasya semakin maju dan berkembang. Beliau terus memikirkan apa yang harus dilakukan untuk mengatasi hal-hal tersebut dan solusi terhadap masalah tersebut sehingga Ibu Saprina menemukan strategi yang diinterpretasikan dari salah satu Asmaul Husna yaitu Ar-Rahman dan Ar-Rahim sebagai strategi yang digunakan. Dimana Ar-Rahman dan ArRahim yang artinya pengasih dan penyayang. ${ }^{3}$ Jadi dapat disimpulkan perlu strategi kasih sayang atau disingkat dengan "kayang" untuk mengatasi permasalahan yang selama ini belum terselesaikan.

Ar-Rahman dan Ar-Rahim adalah Nama Allah atau sifat Allah yang mempunyai pengertian pengasih dan penyayang yang

3 Wawancara dengan kepala PAUD Kasya, Ibu Saprina Siregar pada tanggal 18 Juli 2020. 
disingkat dengan kasih sayang. Kasih sayang disini diberikan kepada semua manusia, baik itu kepada insan yang mengerjakan perintah Allah SWT maupun kepada insan yang tidak mengerjakan perintah Allah SWT atau insan yang mengerjakan apa yang dilarangNya. Allah tetapmemberikan rahmat, rezeki dankaruniaNya kepada kita semua tanpa memikirkan apakah kita mengikuti apa yang diperintahkan ataupun tidak. Allah tidak membeda-bedakan manusia dan tetap memberikan rahmat dan rezekiNya kepada kita semua. Ini yang membuat pimpinan PAUD Inklusi Kasya mengambil kesimpulan bahwa harus membuat strategi yang sama kepada ABK dan Non ABK. Tidak ada pilih kasih atau membeda-bedakan mereka, semua harus sama sehingga lambat laun semua permasalahan yang ada di PAUD Inklusi tersebut dapat teratasi. Strategi "Kayang" ini telah mendapatkan hak paten dari pemerintah dan ibu saprina sudah sering diundang untuk mengisi atau menjadi nara sumber di beberapa pelatihan dan kelas parenting. Bertitik tolak dari fenomena yang terjadi, maka peneliti tertarik untuk mengkaji lebih dalam dan mengangkat permasalahan ini dengan judul "Implementasi strategi "kayang" pada PAUD Inklusi Kasya Day Care Center and School Banda Aceh".

\section{LANDASAN TEORI}

\section{A. Definisi Implementasi}

Makna implementasi menurut Daniel A. Mazmanian dan Paul Sabatier (1979) sebagaimana dikutip dalam buku Solihin Abdul Wahab (2008) mengatakan bahwa: Implementasi adalah memahami apa yang senyatanya terjadi sesudah suatu program dinyatakan berlaku atau dirumuskan merupakan fokus perhatian implementasi kebijaksanaan yakni kejadian- kejadian dan kegiatan-kegiatan yang timbul sesudah disahkannya pedoman-pedoman kebijaksanaan Negara yang mencakup baik usaha-usaha untuk mengadministrasikannya maupun untuk menimbulkan akibat/dampak nyata pada masyarakat atau kejadian-kejadian. ${ }^{4}$ Menurut Nurdin Usman (2002) implementasi adalah bermuara pada aktivitas, aksi, tindakan atau adanya mekanisme suatu sistem, implementasi bukan sekedar aktivitas, tapi suatu kegiatan yang terencana dan untuk mencapai tujuan kegiatan. ${ }^{5}$

Guntur Setiawan (2004) berpendapat, implementasi adalah perluasan aktivitas yang saling menyesuaikan proses interaksi antara tujuan dan tindakan untuk mencapainya serta memerlukan jaringan pelaksana,birokrasi yang efektif $^{6}$

Dalam Harsono (2002:67) Implementasi adalah suatu proses untuk melaksanakan kebijakan menjadi tindakan kebijakan dari politik ke dalam administrasi. Pengembangan kebijakan dalam rangka penyempurnaan suatu program. ${ }^{7}$

\section{B. Definisi Strategi}

David (2006) mengartikan strategi adalah alat untuk mencapai tujuan jangka panjang, merupakan tindakan potensial yang membutuhkan keputusan manajemen tingkat atas dan sumber daya perusahaan/

4 Abdul Wahab, Solichin. Analisis Kebijakan: Dari Formulasi ke Implementasi Kebijakan Negara. Edisi Kedua. Jakarta: Bumi Aksara. 2008. Hlm.65.

5 Nurdin Usman. Konteks implementasi berbasis Kurikulum. Bandung: Sinar Baru. 2002. Hlm.70.

6Guntur Setiawan. Implementasi Dalam Birokrasi Pembangunan. Bandung: Remaja Rosdakarya.2004. Hlm.39.

7Hanifah Harsono. Implementasi Kebijakan dan Politik. Jakarta: Rineka Cipta. 2002. Hlm.67. 
organisasi dalam jumlah yang besar. Strategi juga mempengaruhi kemakmuran perusahaan/ organisasi dalam jangka panjang dan berorientasi masa depan. Strategi memiliki konsekuensi yang multifungsi dan multidimensi serta perlu mempertimbangkan faktor-faktor eksternal dan internal yang dihadapi perusahaan/ organisasi. ${ }^{8}$

Menurut Wina Sanjaya (2006:126) dalam dunia pendidikan strategi diartikan sebagai $a$ plan method, or series of activities designed a particular educational goal, yang artinya sebagai perencanaan yang berisi tentang rangkaian kegiatan yang didesain untuk mencapai tujuan pendidikan tertentu. ${ }^{9}$

\section{Strategi Pembelajaran}

Dalam Sanjaya (2008:126) strategi pembelajaran dapat diartikan sebagai perencanaan yang berisi tentang rangkaian kegiatan yang didesain untuk mencapai tujuan pendidikan tertentu. ${ }^{10}$

Menurut Uno (2008:3) strategi pembelajaran adalah cara-cara yang akan digunakan oleh pengajar untuk memilih kegiatan belajar yang akan digunakan selama proses pembelajaran. Pemilihan tersebut dilakukan dengan mempertimbangkan situasi dan kondisi, sumber belajar, kebutuhan dan karakteristik peserta didik yang dihadapi dalam rangka mencapai tujuan pembelajaran tertentu. ${ }^{11}$

8 David, Fred R. Manajemen Strategi. Buku 1, Edisi kesepuluh. Jakarta: Salemba Empat. 2006. Hlm.1617.

9 Wina Sanjaya,. Strategi pembelajaran berorientasi standar proses pendidikan. Jakarta: Kencana Prenada Media Group. 2006. Hlm. 126.

10 Wina Sanjaya. Perencanaan dan desain sistem pembelajaran. Jakarta: Kencana Prenada Media Group.2008.Hlm. 126.

11 B. Uno, Hamzah. 2008. Teori Motivasi dan Pengukurannya, Jakarta: Bumi Aksara. 2008. Hlm.3.

\section{Strategi Kayang}

Strategi kayang merupakan singkatan dari strategi kasih sayang yang diperkenalkan dan dibuat oleh Ibu Safrina Siregar yang mana strategi ini diambil atau diadopsi dari salah satu Asmaul Husna (Nama-Nama Allah) yaitu Ar-Rahman dan Ar-Rahim. Ar-Rahman dan Ar-Rahim artinya pengasih dan penyayang. Maknanya yaitu rahmat Allah SWT itu luas dan kasih sayangNya akan sampai kepada semua makhluknya. Hal ini dapat dijelaskan bahwa kasih sayang itu bersifat universal. Jadi semua makhluk berhak mendapatkan kasih sayang. Itu berarti tidak memihak, atau netral. Maksud dari ayat ini dikontekskan ke dalam PAUD ini yaitu semua anak baik itu Anak Berkebutuhan Khusus (ABK) dan Non ABK mempunyai hak yang sama dalam pembelajaran, perhatian dan kasih sayang. ${ }^{12}$

\section{E. Paud Inklusi}

Menurut Peraturan Menteri Pendidikan dan Kebudayaan Republik Indonesia nomor 137 tahun 2014 pasal 1, Pendidikan Anak Usia Dini adalah upaya pembinaan yang ditujukan kepada anak sejak lahir sampai usia 6 (enam) tahun yang dilakukan melalui pemberian rancangan pendidikan untuk membantu pertumbuhan dan perkembangan jasmani dan rohani agar anak memiliki kesiapan dalam memasuki pendidikan lebih lanjut. ${ }^{13}$

\section{HASIL PENELITIAN DAN PEMBAHASAN}

12 Wawancara dengan Kepala PAUD Inklusi Kasya, Ibu Saprina Siregar pada tanggal 18 Juli 2020.

13 Peraturan Menteri Pendidikan dan Kebudayaan Republik Indonesia nomor 137 tahun 2014 pasal 1 
Dalam pendidikan, terdapat berbagai macam cara atau strategi pembelajaran yang diterapkan oleh seorang guru atau pengajar. Jadi guru dapat memilih dan menerapkan strategi pembelajaran yang tepat yang dapat diterapkan bagi siswa atau anak didiknya.

PAUD inklusi merupakan lembaga pendidikan yang memiliki tantangan yang sangat berat bagi guru dalam beradaptasi dan mentransfer ilmunya. Karena normalnya murid yang diajarkan yaitu Anak Berkebutuhan Khusus (ABK). Butuh kesabaran dan tehnik yang tidak biasa. Oleh karena itu perlu strategi yang tepat sehingga tujuan pembelajaran akan tercapai dengan maksimal. Setiap PAUD akan mempertimbangkan strategi pembelajaran yang bisa diaplikasikan oleh guru-gurunya dan juga stakeholder sekolah. Begitu juga PAUD Kasya, strategi pembelajaran yang paling tepat yang diterapkan PAUD Kasya yaitu strategi kasih sayang atau disingkat dengan "strategi kayang". Strategi kayang ini diciptakan oleh kepala sekolah PAUD Kasya sendiri.

Menurut Saprina Siregar (2018) dalam "strategi kayang", terapi Kasih Sayang menjadi pilihan untuk menyelesaikan permasalahan di PAUD Kasya, namun dalam implementasinya bukanlah hal yang mudah. Tidak semua orang dengan mudah menunjukkan kasih sayang dalam sikap sehari-hari. Oleh sebab itu, pengelola harus memastikan agar Terapi Kasih Sayang benar-benar terwujud dalam perilaku guru baik itu dalam pembelajaran, kandungan materi pembelajaran, interaksi antar guru, anak, orang tua, dan lingkungan sekitar sekolah. Dalam penerapan terapi ini, diperlukan dasar kebijakan dan mekanisme pemecahan masalah. Terapi Kasih Sayang harus menjadi mainstream seluruh elemen yang ada di PAUD Kasya, bukan hanya pada tatanan konsep normatif akan tetapi pada konsep yang aplikatif juga. ${ }^{14}$

Yang terpenting dalam terapi kasih sayang ini yaitu guru-guru atau tenaga pengajarnya. Mereka harus dapat mengontrol perilaku, sikap, tutur kata dan juga emosi mereka dalam menghadapi anak berkebutuhan khusus dan Non ABK. Dan hal itu bukanlah hal yang mudah. Terapi kasih sayang ini bukan hanya harus diterapkan di sekolah saja, akan tetapi harus dapat juga diterapkan di rumah. Jadi hal ini akan menjadi kebiasaan dan karakter semua stakeholder sekolah. Karena kebiasaan dan lingkungan juga berperan dalam pendidikan anak-anak usia dini.

Dengan tercapainya target pembelajaran, salah satu indikator keberhasilan PAUD Inklusi Kasya saat ini yaitu yang mendaftar bukan hanya Anak yang Berkebutuhan Khusus (ABK), akan tetapi anak-anak Non ABK juga banyak yang mendaftar dan menjadi siswa disana. Kepercayaan dan promosi untuk menyekolahkan siswa-siswa di PAUD Kasya baik itu dari wali murid atau masyarakat merupakan alasan bagi kepala sekolah dan guru-guru PAUD Kasya memberikan pelayanan terbaik dan kasih sayang tulus yang diberikan bagi semua siswa-siswi disana. Hal ini juga dilakukan demi tercapainya tujuan pendidikan yaitu mencetak generasi yang berkarakter dan berakhlak mulia.

\section{KESIMPULAN}

14 Saprina Siregar. Terapi Kasih Sayang di PAUD Kasya. Lomba Karya Nyata. 2018. Hlm.3. 
Strategi pembelajaran yang dilakukan PAUD Kasya merupakan hasil evaluasi dari pembelajaran yang pernah diterapkan. Apapun kondisinya, kasih sayang merupakan jawaban dari permasalahan yang ada khususnya di dunia pendidikan. Apalagi pada PAUD Inklusi, Bukanlah hal mudah bagi guru untuk dapat mengontrol dan mengajarkan Anak Berkebutuhan Khusus, apalagi jika digabungkan antara Anak Berkebutuhan Khusus dan Non Anak Berkebutuhan Khusus. Perlu strategi yang dapat diterapkan dalam memanage semua Anak. Dan strategi yang paling tepat diterapkan di PAUD Kasya yaitu "strategi kayang".

Dengan strategi kayang atau pendekatan kasih sayang, maka tidak akan ada pembedaan perlakuan terhadap anak. Semua anak mempunyai hak dan kesempatan yang sama dalam mengenyam pendidikan. Jadi sudah menjadi tugas bersama baik itu guru, keluarga dan masyarakat agar tujuan pendidikan dapat tercapai dengan maksimal.

\section{DAFTAR PUSTAKA}

Tarmansyah. Inklusi Pendidikan untuk Semua. Jakarta: Depdiknas, 2007.

Abdul Wahab, Solichin. Analisis Kebijakan: Dari Formulasi ke Implementasi
Kebijakan Negara. Edisi Kedua. Jakarta: Bumi Aksara, 2008.

Usman, Nurdin. Konteks Implementasi Berbasis Kurikulum. Bandung: Sinar Baru, 2002.

Setiawan, Guntur. Implementasi Dalam Birokrasi Pembangunan. Bandung: Remaja Rosdakarya, 2004.

Harsono, Hanifah. Implementasi Kebijakan dan Politik. Jakarta: Rineka Cipta, 2002.

David, Fred R. Manajemen Strategi. Buku 1. Edisi kesepuluh. Jakarta: Salemba Empat, 2006.

Sanjaya, Wina. Strategi pembelajaran berorientasi standar proses pendidikan. Jakarta: Kencana Prenada Media Group, 2006.

Sanjaya, Wina. Perencanaan dan desain sistem pembelajaran. Jakarta: Kencana Prenada Media Group, 2008.

B. Uno, Hamzah. Teori Motivasi dan

Pengukurannya. Jakarta: Bumi Aksara, 2008.

Peraturan Menteri Pendidikan dan Kebudayaan Republik Indonesia nomor 137 tahun 2014 Saprina Siregar. Terapi Kasih Sayang di PAUD Kasya. Lomba Karya Nyata. Banda Aceh, 2018. 